Rosnes, M. H., Sheptyakov, D., Franz, A., Frontzek, M., Dietze1, P. D. C., \& Georgiev, P. A. (2017). On the elusive nature of oxygen binding at coordinatively unsaturated $3 d$ transition metal centers in metal-organic frameworks. Physical Chemistry chemical

Physics, 19(38), 26346-26357. https://doi.org/10.1039/c7cp05119k

\title{
On the elusive nature of Oxygen binding at coordinatively unsaturated 3d transition metal centers in metal-organic frameworks
}

\author{
Mali H. Rosnes ${ }^{\mathrm{a}}$, D. Sheptyakov ${ }^{\mathrm{b}}$, A. Franz ${ }^{\mathrm{c}}$, M. Frontzek ${ }^{\mathrm{b}}$ Frontzek $^{\mathrm{f}}$, Pascal D. C. Dietzel ${ }^{\mathrm{a}}$, P. A. \\ Georgiev $^{\mathrm{d}^{*}}$,
}

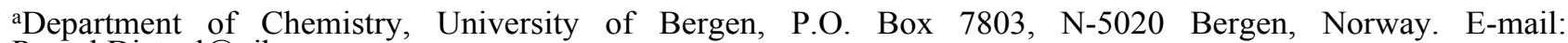
Pascal.Dietzel@uib.no

${ }^{b}$ Laboratory for NeutronScattering, Paul Scherrer Institut, CH-5232 Villigen, Switzerland

fQuantum Condensed Matter Division, Oak Ridge National Laboratory, 37831 Oak Ridge, TN, USA

dDepartment of Chemistry, University of Milan, 21 Via Golgi, I-20133 Milan, Italy.

eFaculty of Physics, University of Sofia, James Bourchier 5, 1164 Sofia, Bulgaria

\begin{abstract}
Using gas sorption measurements at ambient temperature and in situ neutron powder diffraction methods, we have studied the interaction strengths and coordination geometries of $\mathrm{O}_{2}$ and $\mathrm{N}_{2}$ near the non-occupied coordination site (open metal site) in the isostructural MOF structures of the CPO-27-M/M-MOF-74 series (with $\mathrm{M}=\mathrm{Co}, \mathrm{Ni}, \mathrm{Mn}$ and $\mathrm{Cu}$ ). Our experimental observations are compared to periodic quantum chemical model calculations. Contrary to recent computational studies, our results, both experimental and theoretical, unequivocally suggest rather weak interactions between the M(II) coordinatively unsatured centers and the adsorbate molecules, being mainly dispersive and electrostatic in nature, and excluding significant orbital charge transfer effect that could lead to superoxide/peroxide formation. The calculated binding energies appear in good agreement to the measured isosteric heats of adsorption in the range of $10-20 \mathrm{~kJ} / \mathrm{mol}$. These, relatively weak host-guest interactions, lead to a tilted end-on geometry in all of the investigated M(II)-guest molecule adducts.
\end{abstract}

\section{Introduction}

Binding, activation, transport, and controlled release of molecular oxygen are of vital importance for aerobic organisms where the processes typically operate assisted by metaloenzymes $^{1,2}$. Not less important is the role of adsorbed molecular oxygen in its electron 
scavenging role at the surface of photo catalysts such as $\mathrm{CeO}_{2}{ }^{3}$, the $\mathrm{TiO}_{2}$ allotropes anatase and rutile ${ }^{4,5}$, as well as $\mathrm{CeO}_{2} / \mathrm{TiO}_{2}$ hybrid nanomaterials ${ }^{6}$. Direct oxidation of light hydrocarbons to alcohols is another quite tempting and attractive catalytic application of bound $\mathrm{O}_{2}{ }^{7}$ In addition, solid state gas storage via molecular adsorption has recently attracted scientific attention. ${ }^{8}$ Another related and not less important issue is the separation of molecular oxygen from other molecules that are similar in weight and size, such as $\mathrm{N}_{2}$. Metal-organic frameworks (MOFs), also known as porous coordination polymers (PCPs), attract continuously growing attention due to their highly crystalline, porous structures, associated with high specific surface areas. MOF compounds that remain intact after removal of the solvent have generated a lot of interest for their potential applications in fields such as catalysis, gas storage, and gas separation. ${ }^{9-11}$ The permanently porous isostructural MOF series CPO-27-M (Figure 1), also denoted $\mathrm{M}_{2}(\mathrm{dhtp}), \mathrm{M}_{2}($ dobdc) $(\mathrm{dhtp} /$ dobdc $=$ $\left.\mathrm{C}_{8} \mathrm{H}_{2} \mathrm{O}_{6}{ }^{4-}\right)$ or M-MOF-74, where $\mathrm{M}=\mathrm{Co},{ }^{12} \mathrm{Ni},{ }^{13} \mathrm{Mg},{ }^{14} \mathrm{Mn},{ }^{15} \mathrm{Zn},{ }^{16} \mathrm{Fe},{ }^{17,18} \mathrm{Cu},{ }^{19-21}$ and $\mathrm{Cd},{ }^{22}$ has particularly useful properties in adsorption related applications due to the large number of coordinatively unsaturated metal centres which are present in the desolvated form. ${ }^{23}$ This leaves the metal centre with a non-occupied coordination site (open metal site) available for interaction with adsorptives, and renders them potentially interesting for separation of $\mathrm{O}_{2}$ from air. ${ }^{12,23}$ Intriguingly, two bound $\mathrm{O}_{2}$ species have been recently detected in the Fe member of the CPO-27 (MOF-74) family. ${ }^{17}$ A reversible superoxido -complex with thermal stability about 40-60 kJ/mol has been anticipated below $200 \mathrm{~K}$, while an irreversible Fe-peroxide, associated with oxidation change of the $\mathrm{Fe}$ from +2 to +3 , is the stable form near room temperature. ${ }^{17,18}$ Recent computational studies on the binding of $\mathrm{O}_{2}$ and $\mathrm{N}_{2}$, as well as their separation, including the other members of the CPO-27 MOF family ${ }^{26,27}$ suggested very strong binding of $\mathrm{O}_{2}$ on the open metal sites at the $\mathrm{M}(\mathrm{II})$ metal centers, with an intriguing trend in the $\mathrm{O}_{2}$ binding energies increasing in the following order: $\mathrm{Zn}<\mathrm{Cu}<\mathrm{Ni}<\mathrm{Co}<\mathrm{Fe}<\mathrm{Mn}$. The computed binding energy for $\mathrm{N}_{2}$ in the same structure was found to be much lower, which would point towards great potential for application of the material in $\mathrm{O}_{2} / \mathrm{N}_{2}$ 
separation by $\mathrm{O}_{2}$ gettering. The binding energy for $\mathrm{N}_{2}$ was reported to be a dramatic 5 times lower than that of $\mathrm{O}_{2}$ in the case of $\mathrm{Mn}(\mathrm{II})$. In fact, such a large binding energy, of the order of ca. $100 \mathrm{~kJ}$ $\mathrm{mol}^{-1} \mathrm{O}_{2}$ and a significantly elongated $\mathrm{O}_{2}$ bond of $1.4 \AA$ suggests facile oxidation of $\mathrm{Mn}(\mathrm{II})$ to $\mathrm{Mn}(\mathrm{III})$ and the formation of a side-on $\mathrm{Mn}(\mathrm{III})-\mathrm{O}_{2}{ }^{2-}$ peroxido complex which could offer some particularly interesting applications in heterogeneous catalysis. The experimental and theoretical findings mentioned above motivated us to explore the capability for binding and activation of molecular oxygen by several open shell $3 \mathrm{~d}$ metal ions in square pyramidal coordination. The family of isostructural porous MOFs CPO-27-M, with its rigid, thermally relatively stable structure, offers an excellent experimental frame for such studies. To determine the corresponding $\mathrm{O}_{2}$ and $\mathrm{N}_{2}$ isosteric heats of adsorption, $\mathrm{Q}_{\mathrm{st}}$, in the $\mathrm{Mn}, \mathrm{Co}, \mathrm{Ni}$, and $\mathrm{Cu}$ and $\mathrm{Zn}$ materials, we performed adsorption isotherm measurements at a series of ambient temperatures. On a microscopic level, the corresponding $\mathrm{O}_{2}$ adducts were investigated by means of in situ neutron powder diffraction, which is compared to the adsorption behavior at $87 \mathrm{~K}$. Additionally, the $\mathrm{O}_{2}$ and $\mathrm{N}_{2}$ binding energies and corresponding adsorbate complex stereochemistry were elucidated with the aid of DFT based computational studies.

\section{Methods}

Sample synthesis and characterisation. $\mathrm{CPO}-27-\mathrm{M}(\mathrm{M}=\mathrm{Mn}, \mathrm{Co}, \mathrm{Ni}$, and $\mathrm{Cu}$ and $\mathrm{Zn})$ were synthesized and pre-treatment for gas adsorption studies was performed according to already published procedures ${ }^{12-21}$ (details are available in the Supplementary Information). The identity and purity of the materials were ascertained by powder x-ray diffraction measurements in BraggBrentano geometry using monochromatic $\mathrm{Cu} \mathrm{K}_{a 1}$ radiation on a Bruker AXS D8 Advance instrument. Gas adsorption measurements were performed using a BELSORP-max instrument equipped with a low pressure transducer and a turbomolecular pump, allowing measurements with high precision, beginning from very low pressures $\left(p / p_{0}=10^{-8}\right)$. 


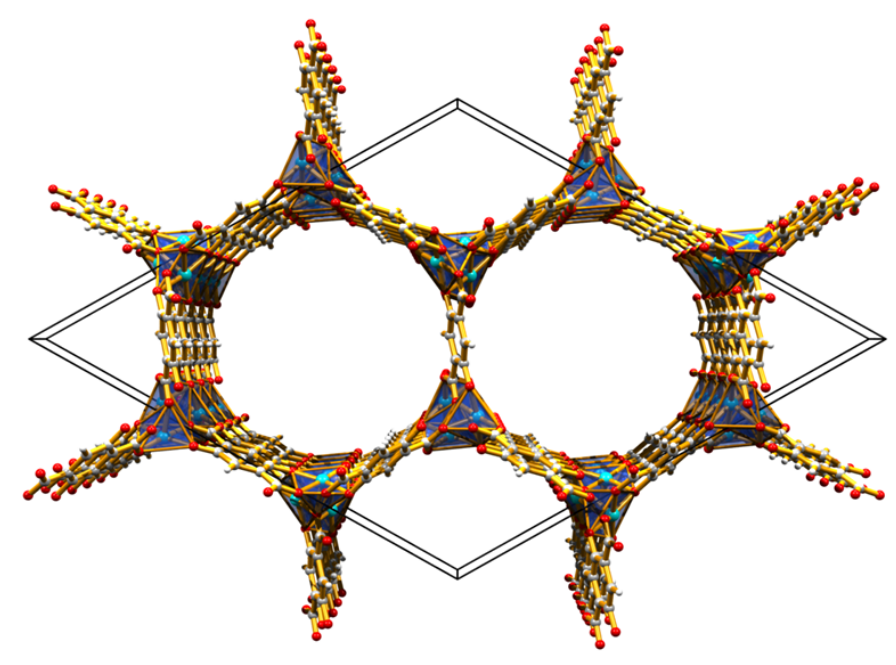

Figure 1. The empty structure of CPO-27-M. The metal cation originally coordinated to a solvent molecule in the solvated form changes on desolvation from octahedral to square pyramidal environment. The now available coordination site can interact with a variety of guest molecules.

The samples were prepared under inert conditions and transferred to the sample cell in a glove box. Prior to the measurements the samples were pre-treated at $453 \mathrm{~K}(\mathrm{Zn}), 423 \mathrm{~K}(\mathrm{Ni}, \mathrm{Mn}$ and $\mathrm{Co})$ and $393 \mathrm{~K}(\mathrm{Cu})$ for 24 hours in a dynamic vacuum. Textural information was obtained from $\mathrm{N}_{2}$ measurements at $77.35 \mathrm{~K}$. For measurements in the range 273-298 K, the temperature was controlled by immersion of the sample cell in an external water bath whose temperature was controlled using a Julabo F25-ME refrigerated/heating circulator with external temperature sensor.

Neutron Diffraction. A desolvated CPO-27-Mn sample $(0.80 \mathrm{~g})$ was measured on the HRPT ${ }^{28}$ instrument (neutron wavelength $1.886 \AA$ ). The same material was subsequently measured on the $\mathrm{DMC}^{29}$ instrument (neutron wavelength $2.45 \AA$ ) dosed in situ with $0.33,1$, and $2 \mathrm{O}_{2}$ per Mn ion. CPO-27-Co $(0.80 \mathrm{~g})$ was measured on the HRPT instrument in desolvated state and loaded in situ with $0.5,1$ and $2.4 \mathrm{O}_{2}$ per Co center. Both instruments are installed at the SINQ neutron source, PSI, Villigen, Switzerland. Samples of CPO-27-Cu and CPO-27-Ni dosed with $1 \mathrm{O}_{2}$ per $\mathrm{Cu}$, and with $0.5,1,1.8$, and $2.6 \mathrm{O}_{2}$ per $\mathrm{Ni}$, as well as $1 \mathrm{~N}_{2}$ per $\mathrm{Ni}$, were measured on the $\mathrm{E} 9$ instrument ${ }^{30}$, at the HZB, Berlin, Germany. Desolvated CPO-27-Ni (1.02 g) and desolvated CPO-27-Cu (0.40 g) were each loaded in vanadium sample containers of $8 \mathrm{~mm}$ diameter and attached to a centre stick 
equipped with a gas capillary, using a He-filled glove bag. Prior to the neutron measurements all samples were additionally evacuated at $453 \mathrm{~K}$ for $\mathrm{Mn}$ and $\mathrm{Ni}, 473 \mathrm{~K}$ for $\mathrm{Co}$, and $393 \mathrm{~K}$ for $\mathrm{Cu}$, for 12 hours in dynamic vacuum with the use of a turbomolecular pumping unit. The $\mathrm{O}_{2} / \mathrm{N}_{2}$ dosing procedures were performed between 200 and $80 \mathrm{~K}$. Adsorption equilibration periods of minimum 30 min were applied for each loading. The neutron diffraction patterns were measured at around 20 $\mathrm{K}$ and below as indicated further in the text. After the end of the final neutron measurement, the adsorbed oxygen was desorbed into a calibrated volume at room temperature. The system was monitored for about $30 \mathrm{~min}$ in each case to check for possible stronger reaction at room temperature, due to possible temperature activated chemisorption. However, there was no observable irreversible binding in any of the tested materials, in contrast to the previously reported peroxide formation in the Fe-material. ${ }^{17,18}$ Crystal structure refinements, based on the collected powder diffraction data, were performed with the use of the Fullprof suite of programs. ${ }^{31}$ The refinement of the CPO-27-Mn wide angle data collected on the HRPT instrument was used as a starting point for the DMC data refinements, in which the atomic displacement parameters of the framework atoms were kept fixed. All other parameters, including all atom coordinates and guest molecule atoms thermal factors, as well as peak shape parameters were refined for all DMC data. The resulting Rietveld refinement plots are shown in Figures S58-S72 and the variation of the corresponding lattice cell parameters, as functions of the guest loading, are depicted in Figure S73.

DFT Calculations: Quantum chemical model calculations on the structure and thermodynamics of the different species adsorbed on CPO-27 materials were performed within the frame of the Density Functional Theory (DFT) and the Generalized Gradient Approximation (GGA), Perdew-Berke-Ernzernhof (PBE) functional with the Projector Augmented Wave (PAW) formalism, as implemented in the ABINIT v.7 software. ${ }^{32,33}$ To prevent self-interaction related errors in the description of the open-shell $3 \mathrm{~d}$ electrons, we included a standard amount of 25\% Harteree-Fock exchange energy in the functional form, 
as implemented in Abinit $\underline{\mathrm{ABINIT}}$, only on the metal ion $3 \mathrm{~d}$ and $\mathrm{N}$ and $\mathrm{O}$ atoms $2 \mathrm{p}$ electrons. Full geometry optimisations of the corresponding 54 atom primitive unit cells of the desolvated materials were carried out, retaining only the translational symmetry of the original space group. The primitive cells were selected so as to be able to efficiently model the corresponding low temperature magnetic structures, containing a chain of 3 metal centers, one with two metal centers and another with one for the desolvated materials ${ }^{34}$, as shown in Figure 2, and the same plus one guest molecule (1/6 per M(II) ion) per primitive unit cell for modelling the adsorbates. A $2 \times 2 \times 2$ supercell representation of this structure is shown in Figure 3, clearly indicates there was no significant deviation from the R-3 symmetry due to the geometry optimisation in the P1 space group. In each case we used a $900 \mathrm{meV}$ energy cut off on the plane wave basis. Total energies were computed only at the Brillouin zone centre. The calculations were checked for convergence with respect to the guest molecule binding energy which appeared of the order of 0.5 to $1 \mathrm{~kJ} \mathrm{~mol}^{-1}$ for the different metals and with respect to plane wave cut off and k-sampling (compared to 1000 $\mathrm{eV}$ on the cut off energy and for a $2 \times 2 \times 2$ shifted $\mathrm{k}$ point grid). Spin polarized calculations were performed for all cases, starting with the AFM1 magnetic order in the case of Fe, Co, and $\mathrm{Ni}$, and AFM2 state for the $\mathrm{Mn}$ - and $\mathrm{Cu}$-materials ${ }^{11,34}$. The AFM1 structure has ferromagnetically ordered spins within one $-\mathrm{O}-\mathrm{M}(\mathrm{II})-\mathrm{O}-$ helical chain, but ions from neighbouring chains are antiferromagnetically ordered. The AFM2 order stands for both intra and interchain antiparallel spin orientations. ${ }^{11,34}$ In all cases the magnetic moments were aligned along the helical chain direction coinciding with c-axis of the unit cell in the present primitive cell choice. Geometry convergence criteria were set to $0.01 \mathrm{eV} / \AA$ during each structure optimisation. The corresponding energy convergence was of the order of $10^{-8}$ $\mathrm{eV}$. The desolvated cells were fully relaxed with no symmetry restrictions, i.e. in space group P1 (Figure 2), while the ones with guest species attached to one of the metal centres 
were isotropicaly relaxed i.e. the lattice vectors were allowed to change their magnitudes while angles between them were kept fixed at the values of the corresponding relaxed desolvated cell. All atomic coordinates were relaxed at each step. This strategy was adopted to model random adsorption, that is no ordering allowed for low adsorbate loadings, at the otherwise crystallographically equivalent metal centres, which should anticipate only some rather small and isotropic (i.e. cell angles kept fixed) unit cell deformation. The total energy of each guest species, with geometry relaxed under the same conditions as above, was evaluated in a box of $16 \times 16 \times 16 \AA^{3}$ size. Dispersion interactions were taken into account during all geometry optimisation procedures, using the empirical correction of Grimme ${ }^{35}$, denoted as GD2 further in the article. In selected cases, for the Co and $\mathrm{Ni}$-compounds, we also performed the calculations for the conventional 54 atom rombohedral cell, in space group R-3, as in previous works, ${ }^{21}$ applying the same chemistries and convergence criteria as above, on a $2 \times 2 \times 2$ Monkhorst-Pack shifted k-point grid. These were extended to higher loadings corresponding to 1,2 , and $3 \mathrm{O}_{2}$ molecules per $\mathrm{Co}$ (or $\mathrm{Ni}$ ) ion to be able to compare to the corresponding experimental neutron diffraction structures. In all investigated cases the triplet ground state of the $\mathrm{O}_{2}$ moleclule remained lower in energy than the first excited singlet state in the corresponding adsorbed states as in the free state, along with the unchanged (with respect to the guest free compound) high spin state of the adsorbent structure. For $\mathrm{N}_{2}$ only the ground singlet ${ }^{2}$ ofolecular state was used in all initial guesses.

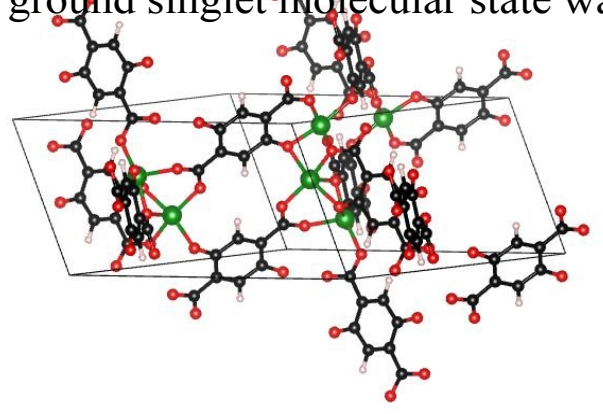


Figure 2. The CPO-27-M(II) primitive unit cell used with no symmetry restrictions. Adsorption of guest molecules was probed at the central ion in the chain containing three metal centers.

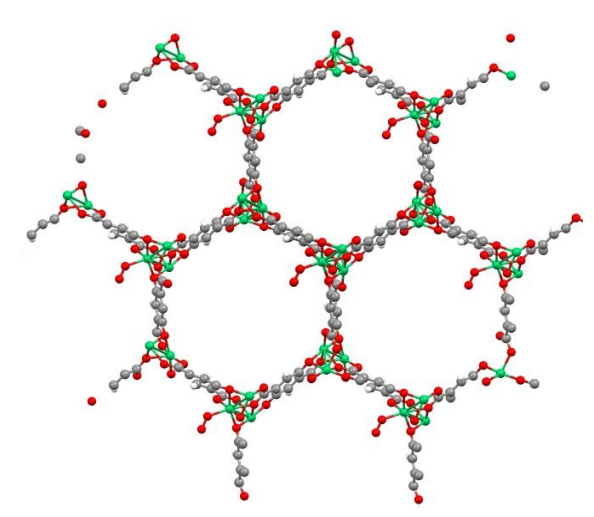

Figure 3. DFT, PBE0 optimized structure of CPO-27-Ni $+1 / 6 \mathrm{O}_{2}$ per $\mathrm{Ni}$ in a $2 \times 2 \times 2$ super cell representation for a better visualization of the complete porous MOF structure. There is one $\mathrm{O}_{2}$ molecule at every three $\mathrm{Ni}$ (II) ions in a chain, at every other chain.

\section{Results and Discussion}

\section{$\mathrm{O}_{2}$ and $\mathrm{N}_{2}$ Gas sorption}

We performed gas sorption measurements of nitrogen at 77 and $87 \mathrm{~K}$ and of oxygen at $87 \mathrm{~K}$ to determine the maximum uptake of the materials. Measurements in the temperature range 273-298 K were used to derive the isosteric heat of adsorption for oxygen and nitrogen.

The nitrogen sorption isotherms at $77 \mathrm{~K}$ and $87 \mathrm{~K}$ show the characteristic trend of the CPO-27 series compounds with their large number of coordinatively unsaturated metal sites. The first molecule of the adsorptive is adsorbed at the metal centre at significantly lower pressures than the second molecule which is visible in the form of steps in the adsorption isotherm (Fig. 4). Analogous steps have been observed for other adsorptives, such as $\mathrm{H}_{2}, \mathrm{CH}_{4}$, and $\mathrm{CO}_{2.1}{ }^{11,35,36}$ All of the CPO-27 compounds investigated here have a maximum uptake of 2.2-2.3 molecules nitrogen per formula unit, except for CPO-27-Mn, for which another step occurs at $p / p_{0}$ corresponding to $\sim 2.2$ molecules 
adsorbed per formula unit, with a final uptake of $\sim 2.6$ molecules $\mathrm{N}_{2}$ per formula unit. The unit cell volume of the empty structure of $\mathrm{CPO}-27-\mathrm{Mn}$ is $5-8 \%$ larger than that of $\mathrm{CPO}-27-\mathrm{Ni}$ and $\mathrm{Co}$, and a small change in unit cell parameters at this $p / p_{0}$ apparently allows more nitrogen molecules to occupy the centre of the channel in CPO-27-Mn than in the other compounds. (See below for structural details of the different adsorption sites in CPO-27.)

We observe a larger number of molecules of oxygen adsorbed in all CPO-27 compounds investigated here at $87 \mathrm{~K}$, compared to the nitrogen uptake (at the same temperature and at $77 \mathrm{~K}$ ). This correlates to the size of the adsorptive molecules. The kinetic diameter of the dioxygen molecule is slightly smaller than that of dinitrogen. The maximum uptake is in the range 2.9-3.3 molecules $\mathrm{O}_{2}$ per formula unit for CPO-27-Ni, Co, and Mn, and $\sim 2.25$ and $\sim 2.6$ molecules $\mathrm{O}_{2}$ per formula unit for $\mathrm{CPO}-27-\mathrm{Cu}$ and $\mathrm{Zn}$, respectively. Intriguingly, the $\mathrm{O}_{2}$ isotherms for the cobalt, nickel, and manganese compound actually show three well-defined steps. Apparently, the $\sim 3$ molecules $\mathrm{O}_{2}$ are adsorbed in consecutive order, which indicates a clear separation in adsorption enthalpies of the three different adsorption sites. The difference between the second and third step is still observable, but much less pronounced for CPO-27-Zn and Fe. In contrast, CPO-27-Cu shows no significant difference in slope of the isotherm for the first and second oxygen molecule adsorbed, indicating energetic equivalence for the two adsorption sites. This is in good agreement with the observation that there is no esential thermodynamic effect of the coordinatively unsaturated metal site on hydrogen adsorption in the copper compound. ${ }^{21}$ Note, however, that there is a step in the nitrogen isotherms at 77 and $87 \mathrm{~K}$. In any case, it is significantly less pronounced than in the other homologues.

The $\mathrm{O}_{2}$ and $\mathrm{N}_{2}$ isotherms at $87 \mathrm{~K}$ reveal that the adsorption of the first two molecules per formula unit of either gas occurs at almost the same pressure for CPO-27-Co, Ni, and $\mathrm{Mn}$, and only small differences are observed for $\mathrm{Zn}$ and $\mathrm{Cu}$. This observation is already an indication that there is no significant difference in interaction strengths between $\mathrm{O}_{2}$ or $\mathrm{N}_{2}$ and the respective CPO-27 
compound at $87 \mathrm{~K}$. This picture changes somewhat around ambient temperature. In the temperature range 273-298 $\mathrm{K}$ all five compounds adsorb to varying degrees more nitrogen than oxygen at a given temperature and pressure (Figures S1-S5), opening up for the possibility that CPO-27-M (M $=\mathrm{Co}, \mathrm{Ni}, \mathrm{Mn}, \mathrm{Zn}$ and $\mathrm{Cu}$ ) might preferentially bind $\mathrm{N}_{2}$ over $\mathrm{O}_{2}$. The difference in uptakes is largest for $\mathrm{CPO}-27-\mathrm{Ni}$ and $-\mathrm{Co}$, whereas the difference is much less for both $\mathrm{CPO}-27-\mathrm{Mn}$ and $-\mathrm{Zn}$, while for $\mathrm{CPO}-27-\mathrm{Cu}$ there is hardly any difference observed. Overall, CPO-27-Ni has the largest uptake of both $\mathrm{N}_{2}$ and $\mathrm{O}_{2}$. 
a)

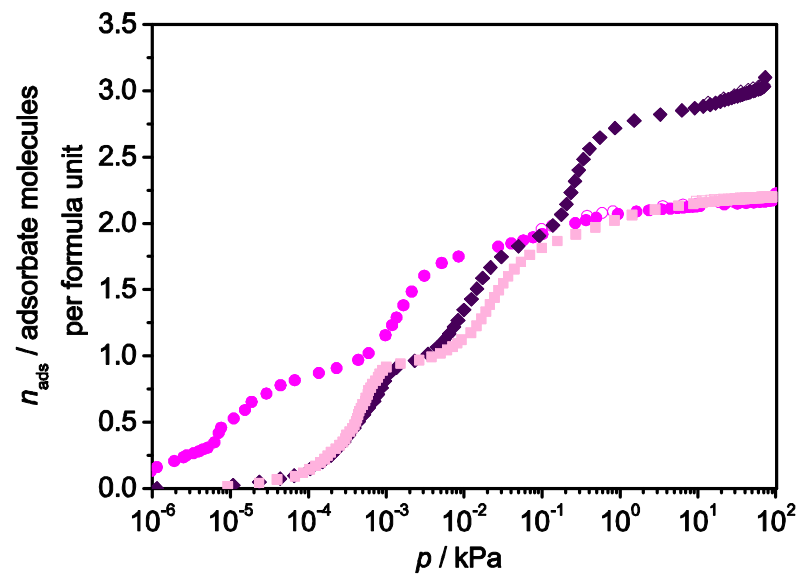

c)

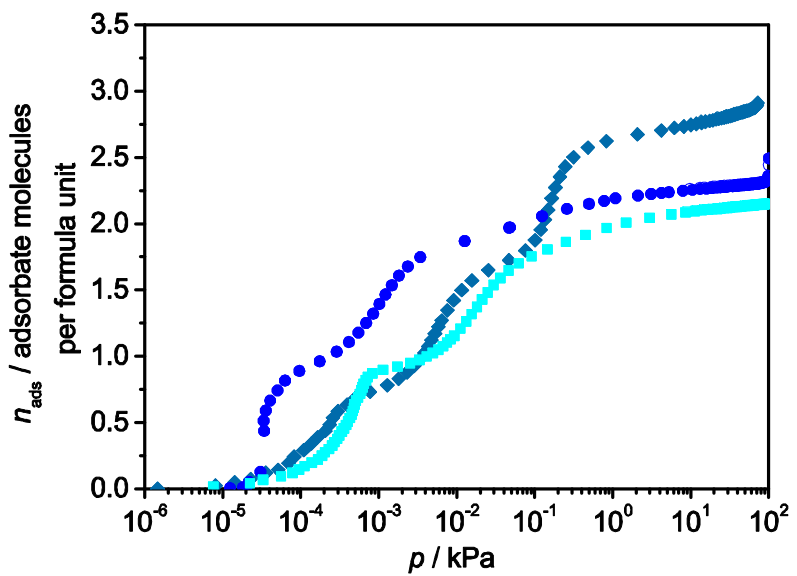

e)

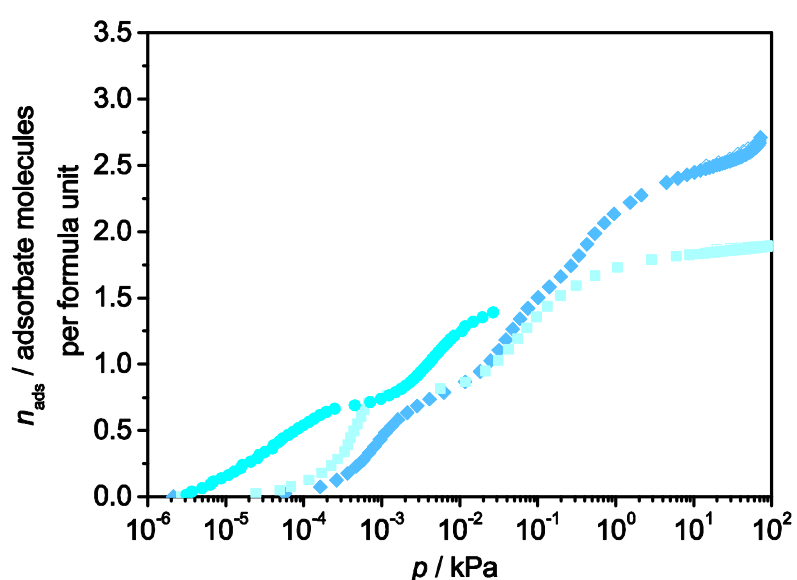

b)

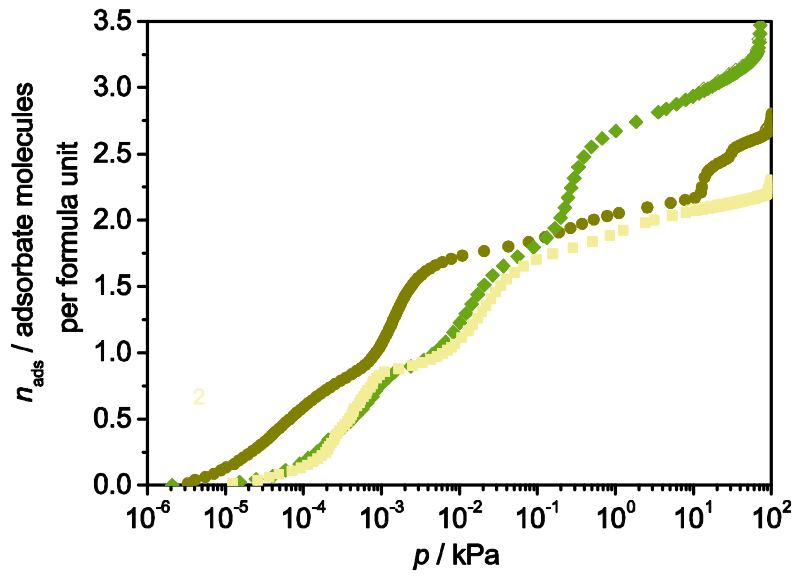

d)

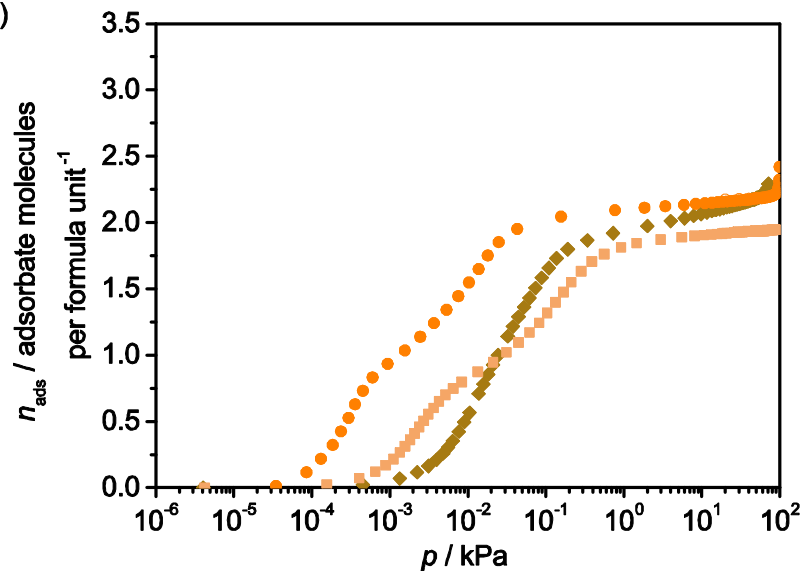

f)

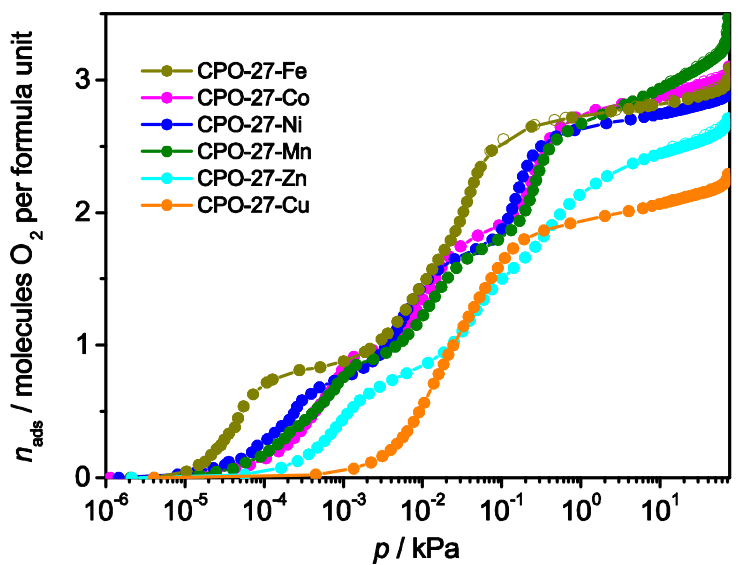

Figure 4. Nitrogen and oxygen sorption isotherms for a) CPO-27-Co, b) CPO-27-Mn, c) CPO-27-Ni, d) CPO-27-Cu, e) CPO-27-Zn (circles: $\mathrm{N}_{2}$ at $77 \mathrm{~K}$, squares: $\mathrm{N}_{2}$ at $87 \mathrm{~K}$, diamonds: $\mathrm{O}_{2}$ at $87 \mathrm{~K}$ ); f) Comparison of the oxygen sorption at $87 \mathrm{~K}$ for the CPO-27 series (data for CPO-27-Fe was taken from ref. 18.

The overall uptake of both nitrogen and oxygen is low for all samples at these temperatures and pressures, but it is particularly low for $\mathrm{CPO}-27-\mathrm{Cu}$ and $\mathrm{Zn}$, for which the sorption data is not of excellent quality, despite using a larger amount of sample. The data for all the five members of the series and for both nitrogen and oxygen adsorption were fitted using the single-site Langmuir- 
Freundlich model (Equation 1, Figures S6-S55, and Tables S1-S13 in the Supplementary Information). The fitting results were then used in the calculation of the isosteric heat of adsorption. The experimentally derived isosteric heats of adsorption, $Q_{\text {st }}$, for $\mathrm{O}_{2}$ and $\mathrm{N}_{2}$, averaged for loadings in the range $0-0.1$ guest molecule per metal center are presented in Table 1 . There is little data in the literature available for comparison: For the case of $\mathrm{Cu}(\mathrm{II})$ in HKUST-1, detailed $\mathrm{O}_{2}$ adsorption data has been measured and the corresponding $Q_{\text {st }}$ estimated as $9.7 \mathrm{~kJ} / \mathrm{mol}^{8}$, which is slightly less than the value of $13.5 \mathrm{~kJ} / \mathrm{mol}$ determined here for CPO-27-Cu (Table 1). It is of course not certain that the measured energetics at ambient temperatures, taking into account the low $Q_{\text {st }}$ values, correspond to adsorption only on the metal ions. More likely, they reflect the isosteric heat of adsorption averaged over all adsorption sites the adsorbate molecule can dynamically occupy at these temperatures. Thus, binding at the secondary site, predominantly due to interaction with oxygen atoms from the organic linker, and at a potential tertiary site, presumably represented by the phenyl ring of the organic linker, also might contribute significantly to the adsorption state in the case of CPO-27, and the measured isosteric heats reflect the respective contribution of the three main sites. The magnitude of each interaction may be estimated by comparison with similar interactions in the literature. It has been reported that isosteric heat of adsorption of $\mathrm{O}_{2}$ at room temperature in activated carbon is in the range $11-13 \mathrm{~kJ} / \mathrm{mol}^{38}$, which might be indicative for the binding affinity at the phenyl ring linker sites. Somewhat lower, at $12 \mathrm{~kJ} / \mathrm{mol} \mathrm{O}_{2}$, is the more recently measured $Q_{\mathrm{st}}$ in Faujasite type zeolite $\mathrm{NaX}^{40}$. A value of only $10 \mathrm{~kJ} / \mathrm{mol}$ for low coverage isosteric heat of adsorption of $\mathrm{O}_{2}$ at room temperature has been reported recently for a highly porous Al-soc-MOF-1 material ${ }^{41}$.

Table 1. Low adsorbate concentration average, ambient temperature isosteric heats of adsorption of $\mathrm{O}_{2}$ and $\mathrm{N}_{2}$ in $\mathrm{CPO}-27-\mathrm{M}(\mathrm{II}), \mathrm{M}(\mathrm{II})=\mathrm{Mn}, \mathrm{Fe}, \mathrm{Co}, \mathrm{Ni}$, and $\mathrm{Cu}$. Distances, where available, are obtained from analysis of the neutron diffraction measurements. 


\begin{tabular}{|c|c|c|c|c|c|}
\hline Metal & $\mathrm{Mn}$ & $\mathrm{Co}$ & $\mathrm{Ni}$ & $\mathrm{Cu}$ & $\mathrm{Zn}$ \\
\hline Molecule & \multicolumn{5}{|c|}{ exp., RT $\mathrm{Q}_{\mathrm{st}}, \mathrm{kJ} / \mathrm{mol}, \mathrm{d}_{\mathrm{M}-\mathrm{X}}, \AA$} \\
\hline $\mathrm{O}_{2}$ & $13.3(4), 2.80(4)$ & $15.6(3), 2.46(1)$ & $17.0(4), 2.23(3)$ & $14(1), 3.06(6)$ & $9(1),-$ \\
\hline $\mathrm{N}_{2}$ & 16.1(3), & $21.2(5), \quad-$ & $23.7(5), 2.30(1)$ & $13.5(3), \quad-$ & $13(1),-$ \\
\hline
\end{tabular}

Table 2.

Computed guest molecule binding energies and $\mathrm{M}(\mathrm{II})$ - nearby guest molecule atom distances

For $\mathrm{CH}_{4}$ the distance between the metal center and the carbon atom is given.

\begin{tabular}{|c|c|c|c|c|c|}
\hline \multirow{2}{*}{ Metal Guest } & $\mathrm{O}_{2}$ & $\mathrm{~N}_{2}$ & $\mathrm{NO}$ & $\mathrm{CO}$ & $\mathrm{CH}_{4}$ \\
\hline & \multicolumn{5}{|c|}{$\mathrm{E}_{\mathrm{b}}, \mathrm{kJ} / \mathrm{mol}, \mathrm{d}_{\mathrm{M}-\mathrm{X}}, \AA$} \\
\hline $\mathrm{Mn}$ & $35.7, \quad 2.105$ & $18.4, \quad 2.630$ & $\begin{array}{ll}57.9, & 2.103\end{array}$ & $37.4, \quad 2.350$ & $27.0, \quad 3.022$ \\
\hline $\mathrm{Fe}$ & $28.9, \quad 2.200$ & $16.3, \quad 2.494$ & $\begin{array}{ll}78.5, & 1.908\end{array}$ & $44.9^{*}, \quad 2.225$ & $27.3, \quad 2.960$ \\
\hline $\mathrm{Co}$ & $19.9, \quad 2.264$ & $\begin{array}{ll}18.4, & 2.547\end{array}$ & $\begin{array}{ll}53.1, & 2.156\end{array}$ & $\begin{array}{ll}43.4, & 2.163\end{array}$ & $25.4, \quad 3.003$ \\
\hline $\mathrm{Ni}$ & $20.1, \quad 2.235$ & $\begin{array}{ll}18.8, & 2.449 \\
\end{array}$ & $\begin{array}{ll}58.4, & 2.107 \\
\end{array}$ & $\begin{array}{ll}49.1, & 2.104 \\
\end{array}$ & $26.2, \quad 2.988$ \\
\hline $\mathrm{Cu}$ & $\begin{array}{ll}12.6, & 2.932\end{array}$ & $\begin{array}{ll}13.6, & 2.829\end{array}$ & $17.1, \quad 2.289$ & $\begin{array}{ll}26.2, \quad 2.309\end{array}$ & $21.7, \quad 3.014$ \\
\hline $\mathrm{Zn}$ & $\begin{array}{ll}16.6, & 2.614\end{array}$ & $\begin{array}{ll}17.6, & 2.701 \\
\end{array}$ & $\begin{array}{ll}39.0, & 2.329 \\
\end{array}$ & $\begin{array}{ll}36.4, & 2.278\end{array}$ & $27.0, \quad 2.973$ \\
\hline
\end{tabular}

"Values calculated assuming AFM1 magnetic order on the Fe(II) ions in the desolvated framework, but. AFM2 order in the $\mathrm{CO}$ adsorbed material as suggested by experimental studies. ${ }^{41}$ See text for details.

Table 3. Computed guest species intramolecular bond distances and metal centre-diatomic species bond angle. Only the average C-H distance is given in the case of $\mathrm{CH}_{4}$. Intramolecular PBE0(GD2) bond lengths and the corresponding experimental values for each guest molecule in the free state are given in the last raw of the table.

\begin{tabular}{|c|c|c|c|c|c|}
\hline \multirow{2}{*}{$\begin{array}{l}\text { Metal Guest } \\
\text { ion }\end{array}$} & $\mathrm{O}_{2}$ & $\mathrm{~N}_{2}$ & $\mathrm{NO}$ & $\mathrm{CO}$ & $\mathrm{CH}_{4}$ \\
\cline { 2 - 6 } & \multicolumn{5}{|c|}{$\mathrm{X}-\mathrm{X}$ bond length, $\AA \quad \mathrm{M}-\mathrm{X}-\mathrm{X}$ angle, deg. } \\
\hline $\mathrm{Mn}$ & $1.290,122.1$ & $1.140,141.7$ & $1.291,122.1$ & $1.147,149.7$ & 1.13 \\
\hline $\mathrm{Fe}$ & $1.283,123.7$ & $1.140,146.0$ & $1.225,143.9$ & $1.150,157.0$ & 1.10 \\
\hline $\mathrm{Co}$ & $1.270,122.1$ & $1.139,143.3$ & $1.202,122.1$ & $1.149,154.1$ & 1.10 \\
\hline $\mathrm{Ni}$ & $1.272,120.8$ & $1.140,142.3$ & $1.202,120.4$ & $1.148,152.5$ & 1.10 \\
\hline $\mathrm{Cu}$ & $1.255,119.0$ & $1.139,137.8$ & $1.198,119.5$ & $1.147,146.1$ & 1.10 \\
\hline $\mathrm{Zn}$ & $1.263,109.0$ & $1.140,141.1$ & $1.198,124.6$ & $1.146,150.9$ & 1.10 \\
\hline Free state & $1.254,1.207^{*}$ & $1.140,1.098^{*}$ & $1.192,1.150^{*}$ & $1.149,1.128^{*}$ & $1.091,1.087^{*}$ \\
\hline
\end{tabular}

* Tables of Interatomic Distances and Configuration in Molecules and lons, L.E. Sutton, ed., London: The Chemical Society, 1958.

A higher value of $16.3 \mathrm{~kJ} \mathrm{~mol}^{-1}$ has been measured for $\mathrm{O}_{2}$ adsorption in silicalite ${ }^{39}$, which may be used as a reference for $\mathrm{O}_{2}$ adsorption at the oxygen atom environment - the secondary $\mathrm{O}$-sites in our case. The isosteric heats determined in this way, are indicative of the physisorption nature of the 
binding of both $\mathrm{N}_{2}$ and $\mathrm{O}_{2}$ in the presently and previously ${ }^{8,41}$ studied porous MOF materials, which is also consistent with the theoretical and neutron scattering results presented below. Their magnitudes are comparable to the corresponding latent heats of $\mathrm{O}_{2}$ and $\mathrm{N}_{2}$ of 6.8 and $5.6 \mathrm{~kJ} / \mathrm{mol}$, respectively.

\section{Computational Results}

Computed binding energies and geometries for the adsorption of guest molecules at the M(II) centers in the CPO-27 framework are listed in Tables $1-3$. For $\mathrm{Mn}(\mathrm{II})$, at a $2 \times 2 \times 2 \mathrm{k}$-point grid the computed binding energy decreased only by a negligible fraction from 35.7 to $35.2 \mathrm{~kJ} \mathrm{~mol}^{-1}$ for the corresponding Gamma point calculation presented in Table 1. Hence, the binding energies at the other M(II) ions were calculated only at the Gamma point. As seen in the data in Table 1, for all measured materials, the interactions between the corresponding coordinatively unsaturated metal center and the guest are either stronger for $\mathrm{N}_{2}$ than $\mathrm{O}_{2}$, or very similar, contrary to the previous theoretical DFT, PBE results. ${ }^{26,27}$ Using both pure GGA, PBE and GGA+U corrected PBE functional in our study to calculate binding energies for $\mathrm{O}_{2}$ at the $\mathrm{Mn}$ (II) site also lead to values in excess of $100 \mathrm{~kJ} \mathrm{~mol}^{-1}$. We therefore attempted a different approach by introducing $25 \%$ HartreeFock exchange in the energy functional, acting only on the $3 \mathrm{~d}$ electrons of the corresponding metal ion and the $2 p$ electrons of both $\mathrm{O}_{2}$ and $\mathrm{N}_{2}$. This resulted in a significant reduction in the computed binding energies, especially for $\mathrm{O}_{2}$, but did not completely remove the known DFT associated electron delocalization and self-interaction effects, which are particularly strong in open shell systems. ${ }^{42}$ Within the same theoretical model frame as for oxygen and nitrogen, we also estimated the interactions at the $\mathrm{M}(\mathrm{II})$ centres of the CPO-27 (MOF-74) framework with $\mathrm{NO}, \mathrm{CO}$, and $\mathrm{CH}_{4}$ guest species, Tables 2, and 3. In the case of $\mathrm{CO}$ adsorbate at $\mathrm{Fe}(\mathrm{II})$, even at the low concentration of $1 \mathrm{CO}$ per $6 \mathrm{Fe}(\mathrm{II})$, probed in our model, the minimum energy structure becomes the one with AFM2 order as suggested by in situ magnetic measurements. ${ }^{43}$ It should be noted that in the desolvated state, the AFM1 order is more stable by about $7.5 \mathrm{meV} / \mathrm{Fe}(\mathrm{II})$ than the FM order. Somewhat counterintuitively, with the other strong ligand, NO, the AFM1 order remained in the minimum energy state. The magnetic order for desolvated and loaded structures remained always AFM1 for $\mathrm{Co}(\mathrm{II})$ and $\mathrm{Ni}(\mathrm{II})$, and AFM2 for $\mathrm{Mn}(\mathrm{II})$ and $\mathrm{Cu}(\mathrm{II})$, with negligible energy difference to the AFM1 order for the later, indicating that the framework would not show magnetic ordering at very low temperatures. As for the low fractional loading results obtained in space group P1, for the stoichiometric loadings of 1 guest molecule per 1 metal center, probed for the Co- and $\mathrm{Ni}$ - 
frameworks, where the R-3 primitive cell was used, the $\mathrm{O}_{2}$ moments aligned again antiferromagnetically with respect to the neighbouring M(II) ion moment.

Table 5. Computed magnetic moments on $\mathrm{Co}(\mathrm{II})$ and $\mathrm{Ni}(\mathrm{II})$ ions for the desolvated and loaded with different amounts of $\mathrm{O}_{2}$ in the CPO-27 structure in its conventional R-3 space group rhombohedral setting. Magnetic moments on the $\mathrm{O}$ atoms of the $\mathrm{O}_{2}$ molecule are listed as well. Negative sign stands for antiparallel alignment of the $\mathrm{O}$ atom magnetic moment with respect to the neighboring $\mathrm{Co}$ or $\mathrm{Ni}$ ion magnetic moment.

\begin{tabular}{|c|c|c|c|c|}
\hline \multirow{2}{*}{$\begin{array}{l}\text { Metal } \\
\text { Ion }\end{array}$} & empty & $+1 \mathrm{O}_{2}$ & $+2 \mathrm{O}_{2}$ & $+3 \mathrm{O}_{2}$ \\
\hline & \multicolumn{4}{|c|}{$\mu_{\text {Bohr }}$ for $\mathrm{M}(\mathrm{II})$ and on each O-atom of the $\mathrm{O}_{2}$ at sites I, II, and III } \\
\hline \begin{tabular}{l}
\multicolumn{1}{c}{ Co } \\
$\mathrm{O}_{2}$ on $\mathrm{Co}$ \\
$\mathrm{O}_{2}$ on $\mathrm{O}-$-ligands \\
$\mathrm{O}_{2}$ in pore inter.
\end{tabular} & 2.73 & $\begin{array}{l}2.71 \\
-0.79,-0.65\end{array}$ & $\begin{array}{l}2.71 ; \\
-0.79,-0.65 \\
0.82,0.82\end{array}$ & $\begin{array}{l}2.71 \\
-0.79,-0.64 \\
0.82,0.82 \\
0.82,0.82\end{array}$ \\
\hline $\begin{array}{l}\quad \mathbf{N i} \\
\mathrm{O}_{2} \text { on } \mathrm{Ni} \\
\mathrm{O}_{2} \text { on } \mathrm{O} \text {-ligands } \\
\mathrm{O}_{2} \text { in pore inter. }\end{array}$ & 1.70 & $\begin{array}{l}1.78 ; \\
-0.81,-0.69\end{array}$ & $\begin{array}{l}1.78 \\
-0.81,-0.69 \\
0.82,0.82\end{array}$ & $\begin{array}{l}1.78 \\
-0.81,-0.69 \\
0.82,0.82 \\
0.82,0.82\end{array}$ \\
\hline
\end{tabular}

The second and third $\mathrm{O}_{2}$ guest molecule atom magnetic moments, adsorbed near secondary and tertiary sites were both found antiparallel to the ones in the first $\mathrm{O}_{2}$ molecule at the primary site, Table 5. Although the computational accuracy of our model may not be high enough to reliably predict such tiny energetic effects, in the case of $\mathrm{Fe}(\mathrm{II})$ it has been experimentally observed, via macroscopic magnetic measurements, that strong ligands do alter the magnetic order, while weak ligands only reduce the magnetic coupling constants. ${ }^{44}$ With respect to the focus of the present work, namely the adsorption thermodynamics of the investigated guest species, and related guest M(II) adduct structure, although GGA functionals with exchange part closely matching exact exchange such as revPBE ${ }^{45}$ and $\mathrm{RPBE}^{46}$ would be also interesting to test due to their relatively low computational cost, hybrid functionals, such as the traditionally used for adduct thermochemistry computations $\mathrm{B} 3 \mathrm{LYP}^{47}$, on the other hand, might give better agreement to experiment, but remain outside our computational resources at present. The deficiency of pure DFT functionals in predicting binding energies of adduct molecules at metal centers, however, is well known and is due to underestimation of the HOMO - LUMO gap of the resultant system. This leads to a false hybridization of the guest molecule frontier orbitals with metal $4 \mathrm{~s}$ and $3 \mathrm{~d}$ states, with the later particularly strong in open shell systems, and especially on undercoordinated metal centers such as in porous MOFs and zeolites. The problem is usually tackled by adding a certain portion exact exchange to the density functional as in the hybrid functional e.g. B3LYP, PBE0. The triplet ground state molecule $\mathrm{O}_{2}$ bound to an open shell $3 \mathrm{~d}$ metal ion constituent structure investigated here seems like a prominent example. However, despite the use of $25 \% \mathrm{HF}$ exchange in the energy functional 
on frontier metal ion and guest species orbitals, the overestimation of the binding energy on metal ions with unpaired electrons in the $d$ shell is still observable in the dependence of the experimental $Q_{\text {st }}$ and the computed $E_{\mathrm{b}}$ on the $\mathrm{M}(\mathrm{II})$ ion (Figure 5). As can be seen in the same figure, we have obtained quite good agreement for $\mathrm{N}_{2}$, where ca. $90 \%$ of the computed binding energy is due to dispersive interactions, represented by the Grimme D2 term.
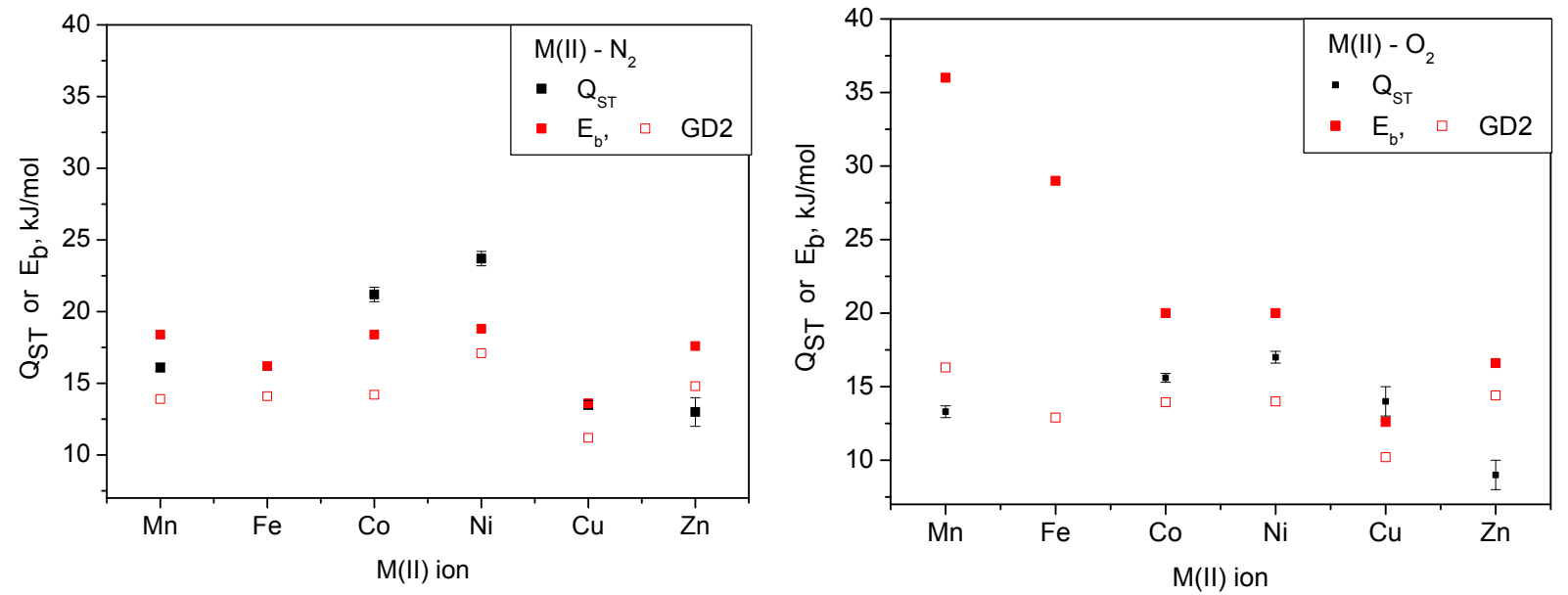

Figure 5. Isosteric heat of adsorption, $Q_{\mathrm{st}}$, and computed binding energy, $E_{\mathrm{b}}$, for $\mathrm{N}_{2}$ on the left block, and $\mathrm{O}_{2}$, right block, vs. M(II) in the CPO-27 structure. GD2 is the Grimme D2 dispersion component in the binding energy.

On the other hand, the computed binding energy for $\mathrm{O}_{2}$ on the half filled $3 \mathrm{~d}$ shell $\mathrm{Mn}$ (II) is overestimated by more than a factor of 2 , with all the error due to an obviously artificial chemical interaction, leaving the dispersive term below $50 \%$ of the total binding (Fig. 5). It would be of some fundamental and practical interest to compare the results of these in part PBE0 ${ }^{48}$ hybrid functional results, being already reasonably close to the experimental results, to those of all electron hybrid DFT and higher level ab initio calculations. When such specific open shell complex cases are not treated with care, errors in the pure DFT estimated binding energies may amount to an order of magnitude ${ }^{27}$ as compared to experimental data. Notably, non-periodic cluster methods, combined with the meta GGA local functionals M06-L and M11-L provide reasonable agreement to experiment with best match for the hybrid version (27\% HF exchange) M06, in the case of the Fe(II)-based material. ${ }^{49}$ However, no test has been made for the $\mathrm{Mn}(\mathrm{II})$ analogue, for instance, where the measured isosteric heat of $\mathrm{O}_{2}$ adsorption is much smaller to the one measured in the 
$\mathrm{Fe}(\mathrm{II})$ case, which is difficult to rationalize if we assume that in both cases the hosts always remain in their high spin states, no change in the corresponding oxidation states occurs, neither significant charge transfers processes are evident, with the guest $\mathrm{O}_{2}$ also remaining in its triplet ground state as in the free state. One would then expect that the interactions at the pentacoordinated Fe(II) center would also be dominated by electrostatic and dispersive contributions which are unlikely to exceed the binding at $\mathrm{Co}$ (II) or $\mathrm{Ni}$ (II) by much. However, it should be pointed out that, in contrast to the $\mathrm{O}_{2}$ sorption energetics, DFT $+\mathrm{U}$ studies on $\mathrm{CO}$ adsorption at $\mathrm{M}(\mathrm{II})$ centers in the CPO-27 structure have achieved quite accurate binding energies. ${ }^{49}$ Our computed PBE0-like values match their experimental values ${ }^{50}$, with the largest deviation of a few $\mathrm{kJ} / \mathrm{mol}$ for $\mathrm{Mn}(\mathrm{II})$, possibly due to the more rigid approach used by us, adding a fixed amount of HF exchange in all of the tested cases. Going further to the NO molecule with doublet ground electronic state, we observed stronger binding at all studied $\mathrm{M}(\mathrm{II})$ ions with respect to $\mathrm{CO}$, except for $\mathrm{Cu}(\mathrm{II})$, for which the order is reversed with a substantial preference for $\mathrm{CO}$, by $9 \mathrm{~kJ} \mathrm{~mol}^{-1}$. This is yet another peculiar property of the $\mathrm{CPO}-27-\mathrm{Cu}$ analogue in the series. $\mathrm{NO}$ is a well known probe molecule for $\mathrm{Cu}(\mathrm{II})$ species in zeolites $^{50}$, where, as a rule of thumb, it binds to various $\mathrm{Cu}$ (II) species much stronger than $\mathrm{CO}$. Nearly constant binding energy with respect to the metal center is computed for $\mathrm{CH}_{4}$ adsorption, in line with earlier experimental and computational studies. ${ }^{11}$ The computed binding energy reported herein appeared to be entirely dominated by the dispersion Grimme $\mathrm{D}_{2}$ term, ranging between $26 \mathrm{~kJ}$ $\mathrm{mol}^{-1} \mathrm{CH}_{4}$ for $\mathrm{Mn}(\mathrm{II})$ to $27 \mathrm{~kJ} \mathrm{~mol}^{-1} \mathrm{CH}_{4}$ for $\mathrm{Zn}(\mathrm{II})$. For the weaker $\mathrm{Cu}(\mathrm{II})$ ion, ${ }^{21}$ the Grimme D2 term is slightly larger than the total binding energy, $22.4 \mathrm{~kJ} \mathrm{~mol}^{-1} \mathrm{CH}_{4}$ compared to $21.7 \mathrm{~kJ} \mathrm{~mol}^{-1}$ (Table 2), probably due to a significant mismatch between the minimum position of the potentials of the pure PBE and the dispersive potential curves. Clearly, one needs a precise description of the involved, often dominating, dispersive interactions to accurately predict the thermochemistries and geometries of the investigated small molecule adsorbates, and they must be incorporated in a 
functional form able to take care of spin effects and correct band gap description of the whole complex system.

\section{Neutron Powder Diffraction}

A direct microscopic insight into the sorption phenomena discussed above was accomplished with the use of in situ gas adsorption neutron diffraction techniques. These provided further evidences of a rather weak interaction between the $\mathrm{N}_{2}$ and $\mathrm{O}_{2}$ guest molecule and the metal centers in the CPO27 structures. In all tested cases $(\mathrm{M}=\mathrm{Mn}, \mathrm{Co}, \mathrm{Ni}, \mathrm{Cu}$, and $\mathrm{Zn})$, the observed $\mathrm{M}(\mathrm{II})$-guest molecule distances, ranging between $2.3 \AA$ on $\mathrm{Ni}(\mathrm{II})$ and $3.1 \AA$ on $\mathrm{Cu}(\mathrm{II})$, do not indicate chemical bonding between host and $\mathrm{O}_{2}$ guest, but rather that physisorption is responsible for the corresponding hostguest adduct formation of relatively low stability. The neutron diffraction results at low loadings, up to 1 adsorbate molecule per formula unit (f.u.), are listed in Table 1. As expected, the largest deviation from the computed values is observed in the case of the half-filled shell of $\mathrm{Mn}$ (II) ion - by about $0.5 \AA$ in our model and $0.8 \AA$ in an earlier DFT study. ${ }^{26}$ Notably, as the number of unpaired electrons in the $3 \mathrm{~d}$ shell of the M(II) center decreases, the errors in both binding energy and M(II) $\mathrm{O}_{2}$ adduct distance are reduced to just a few $\mathrm{kJ} \mathrm{mol}^{-1}$ and about $0.1 \AA$ (Table 1 and 2 ).
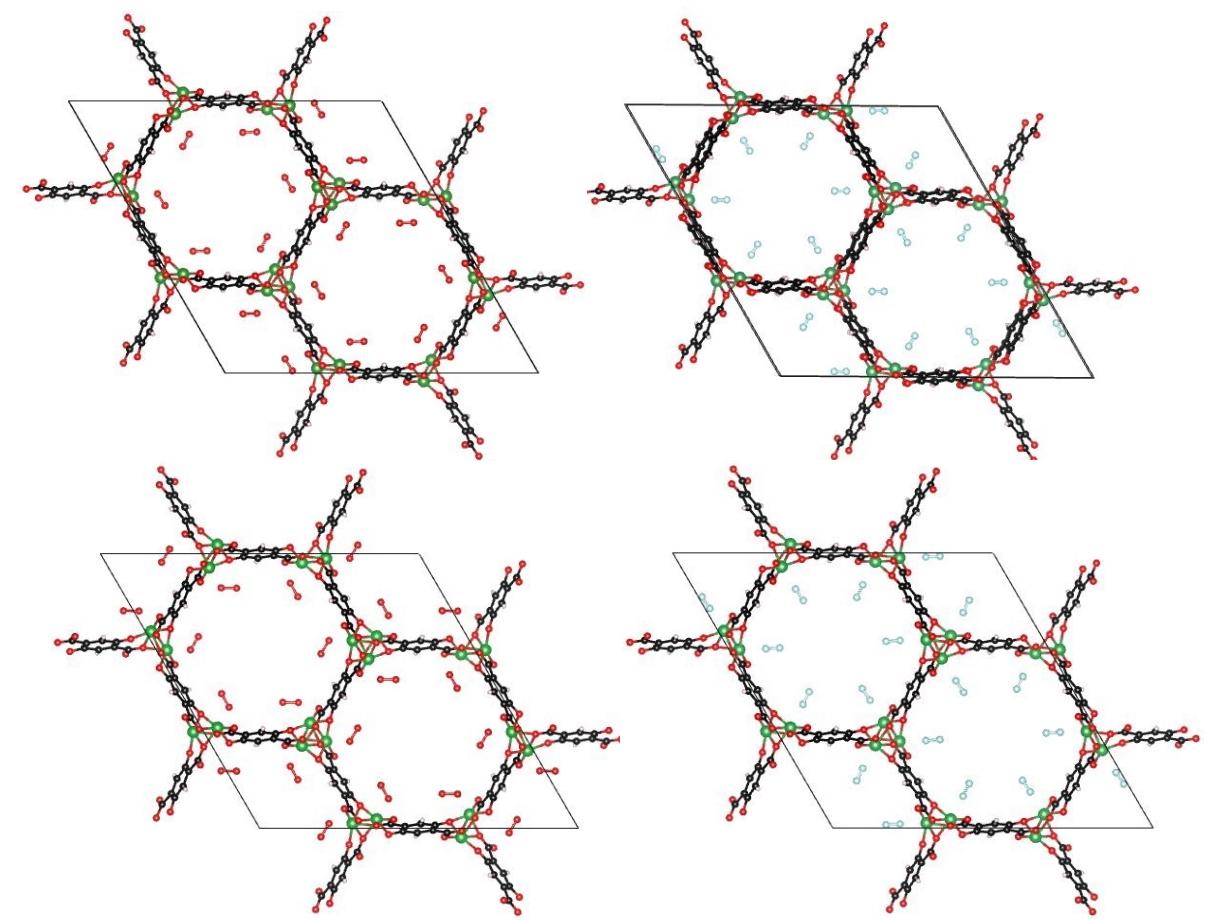

Figure 6. Top: Neutron powder diffraction structures of CPO-27-Ni loaded with 1 molecule $\mathrm{O}_{2}$ per $\mathrm{Ni}$ (II), on the left, and the same material loaded with 1 molecule $N_{2}$ per Ni-site on the right. Bottom: Same structures as resulting from the simulations. 
While no accurate value for the bond lengths of the adsorbed $\mathrm{O}_{2}$ and $\mathrm{N}_{2}$ species could be derived from the neutron diffraction data, probably due to a too large orientational disorder of the adsorbate molecules, we can conclude with moderate accuracy that an end-on coordination is preferred in all the cases studied herein, in agreement with our DFT simulations. As also predicted by the computational models, the $\mathrm{O}_{2}$ molecule, being in an end-on configuration with respect to the nearby M(II) centre, is tilted so as to lie nearly parallel to one of the phenyl rings of the organic ligand, while $\mathrm{N}_{2}$ points almost radially towards the pore interior (Figure 6). We attempted to refine the diffraction data by modeling the adsorbed $\mathrm{O}_{2}$ molecule as a single $\mathrm{O}$ atom and shaping it through the corresponding anisotropic thermal parameters. The refinements (crystal structure data is available as cif files as part of the Supporting information) converged to only marginally worse fit quality parameters, while the corresponding adsorbate molecule thermal ellipsoids again indicated an end-on coordination mode (Figure 7). The corresponding metal center-to-O atom distances, now being 2.59(4), 2.50(1), 2,43(2), and 3.32(4) $\AA$ at $\mathrm{Mn}, \mathrm{Co}, \mathrm{Ni}$, and $\mathrm{Cu}$ accordingly, were consistent with the ones in Table 1, correctly following the trend in the measured $\mathrm{Q}_{\text {st }}$.

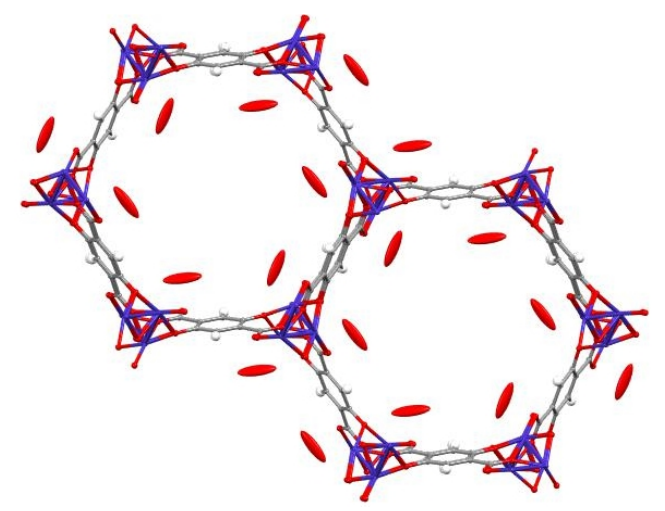

Figure 7. Crystal structure of CPO-27-Co loaded with $1 \mathrm{O}_{2}$ molecule per f.u. from Rietveld refinement of neutron diffraction data. The adsorbed $\mathrm{O}_{2}$ molecule was modelled as a single atom with anisotropic thermal parameters. Allowing for double site occupancy, a refined O-loading of 1.93(3) was obtained.

At higher $\mathrm{O}_{2}$ loadings between 1 and $2 \mathrm{O}_{2}$ molecules per formula unit, which correspond to the second plateau in the corresponding adsorption isotherm (Figure 3), the space between the primary adsorption sites at the pore corners is occupied with guest molecules, and a chain like adsorbate 
structure is formed (Figure 8). Oxygen atoms from the carboxylate units of the linker ligand mainly constitute the adsorbent surface defining the secondary adsorption sites.

To further test our computational model predicting a maximum of 3 guest molecules of $\mathrm{O}_{2}$ adsorbed in both $\mathrm{CPO}-27-\mathrm{Co}$, and $\mathrm{Ni}$, we tried to load as much oxygen as possible in both frameworks, at temperatures as low as $90 \mathrm{~K}$.

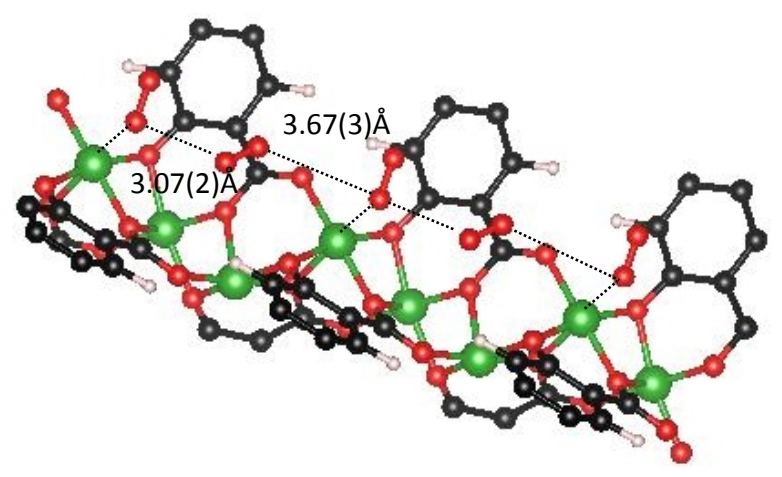

Figure 8. Structural excerpt of CPO-27-Ni loaded with $1.8 \mathrm{O}_{2} /$ f.u. representing the secondary $\mathrm{O}_{2}$ sites inserted between the primary sites at the metal cation, as obtained from the neutron diffraction structure refinement.

The maximum loadings attained were 2.4 and $2.6 \mathrm{O}_{2}$ per $\mathrm{Co}(\mathrm{II})$ and $\mathrm{Ni}(\mathrm{II})$, respectively, comparing favorably to the maximum uptakes measured in the oxygen adsorption experiments at $87 \mathrm{~K}$. Unfortunately, the corresponding Rietveld refinement results suffer from unphysically large mean square displacements of the guest atoms.
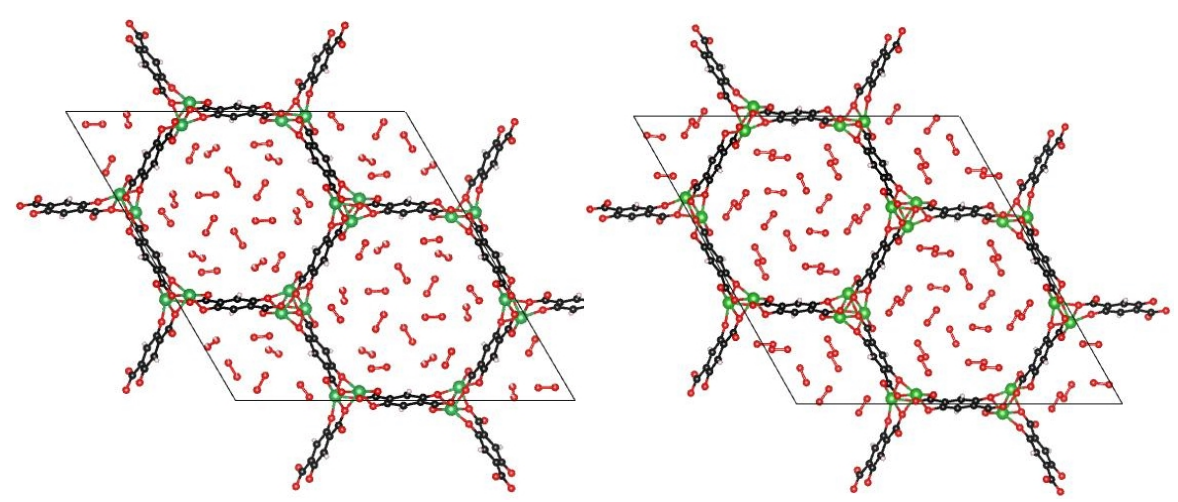

Figure 9. Crystal structure of CPO-27-Ni loaded with 2.6 $\mathrm{O}_{2}$ molecules per f.u. from Rietveld refinement of neutron diffraction data (left) and the same material modelled with $3 \mathrm{O}_{2} /$ f.u after full geometry relaxation as explained in the text (right). In both cases the molecules where forced into three crystallographically distinct positions. 
They are most likely due to a large static disorder of the adsorbate molecules in the pore interiors and are particularly large in the Co material. Figure 9 shows the resulting structures for the Ni compound, along with the same from the periodic PBE0 simulations. It is worth pointing out that in the case of water and hydrogen, near the corresponding boiling points of the two adsorbates, much larger capacities of ca. 5 guest molecules per formula unit are attained. ${ }^{21}$ In contrast to $\mathrm{H}_{2}\left(\mathrm{D}_{2}\right)$ adsorbates of CPO-27, ${ }^{21}$ for which a third adsorption site at the phenyl ring is available, this site is now blocked by the larger, farther lying, and tilted $\mathrm{O}_{2}$ molecules at the metal site. Thus, increasing the loading above 2 guest molecules per f.u. already leads to filling of the pore interiors. Such adsorbate molecules are not directly in contact with the host surface, i.e. they effectively form a second molecular layer. For these adsorbate molecules, the adsorbate-adsorbate interactions are expected to become significant and at a certain point even exceed the adsorbate-host interactions. Consequently, pore interior molecular structures may not necessarily be described within the same symmetry as the host structure. Thus, enforcing the same structural model on these interior structures may not be justified. In fact, spreading the adsorbate into just three crystallographically distinct sets of adsorption sites for total loadings of 3 guest molecules per f.u. as in Figure 9, leads to very low computed by the DFT simulations binding energies. For the molecules in the pore center of the $\mathrm{Ni}$ - and Co-frameworks the computed binding energies are below $2 \mathrm{~kJ} \mathrm{~mol}^{-1}$. Although these stoichiometric model structures lead to Rietveld fits of good quality, with corresponding computed binding energies that are about a factor of three lower than the corresponding latent heats of bulk $\mathrm{O}_{2}$ and $\mathrm{N}_{2}$, they do not seem to be physically correct. It is likely that allowing for some nonstoichiometricity on the guest site occupation in the pore may help to achieve more flexible and optimal packing. Introducing a fourth site clearly produces a better fit of the experimental data for CPO-27-Co dosed with $2.4 \mathrm{O}_{2}$ per f.u. The corresponding cif file is provided in the Supplementary information. This nonstoichiometric manner of pore filling with relatively large thermal parameters indicates that we are already at the onset of disorder with respect to the host structure symmetry. 
While accurate guest atom position determination was impossible from our high loadings above 2 guest molecules per f.u. data sets, the fits were good enough to output the dependence of the corresponding lattice cell parameters on the guest loading. For all measured materials, loading with $\mathrm{O}_{2}$ clearly leads to a decrease of the a lattice cell parameter, which means the pore diameter contracts, and a small increase of the $\mathbf{c}$ lattice parameter. For CPO-27-Co and Ni this behavior can be traced to the highest attainable loadings of 2.4 and $2.6 \mathrm{O}_{2}$ molecules per f.u., and could be attributed to significant long range attractive adsorbate-adsorbate interactions, supporting the arguments above and further indicating that the computational model with 3 crystallographic positions is inadequate. The opposite seems to happen for $\mathrm{N}_{2}$, for which even at $1 \mathrm{~N}_{2}$ per $\mathrm{Ni}$ ion, both cell parameters increase. This is reflected in the lower maximum uptake of $\mathrm{N}_{2}$ compared to $\mathrm{O}_{2}$ in the corresponding low temperature sorption isotherms of these materials, shown in Fig. 3.

\section{Conclusions}

Using experimental thermodynamic and neutron scattering methods as well as theoretical quantum chemistry computational models, we have studied the interactions of $\mathrm{O}_{2}$ and $\mathrm{N}_{2}$ with coordinatively unsaturated divalent open shell metal ions, which are an essential structural part of the CPO-27 porous coordination polymers. Adsorption isotherms near the boiling points of the adsorbates show three steps corresponding to three groups of adsorption sites with different adsorption energetics. Neutron diffraction experiments identified these sites as: 1) at the coordinatively unsaturated M(II) ions, 2) in the vicinity of $\mathrm{O}$ atoms of the linker ligands, between primary sites at the metal ions, 3 ) pore interiors. The magnitudes of the measured isosteric heats of adsorption of $\mathrm{O}_{2}$ and $\mathrm{N}_{2}$ at ambient temperatures and pressures, and the host-guest structures determined from neutron diffraction experiments at low temperatures as well as hybrid DFT simulations, indicate rather weak binding even at the open metal sites, typical for electrostatic and dispersive interactions. Around ambient temperature, CPO-27-Ni has the highest heat of adsorption for both nitrogen and oxygen in 
the series, successively followed by Co and then Mn. Intriguing differences in trends are observed for CPO-27-Mn, $\mathrm{Cu}$ and $\mathrm{Zn}$. The isosteric heat of adsorption for $\mathrm{O}_{2}$ in $\mathrm{CPO}-27-\mathrm{Cu}$ is very similar to that observed for CPO-27-Mn, and significantly larger than that for CPO-27-Zn. The isosteric heat of adsorption of $\mathrm{N}_{2}$ in both CPO-27-Cu and - Zn are almost identical and the value for CPO-27-Mn is slightly larger.

No superoxide or peroxide complex formation was found for any of the studied structures, neither at low nor ambient temperatures. Although our experimental data represent a good reference frame for testing theoretical models, especially valuable in the case of open shell systems like interactions with molecular oxygen, the observed $\mathrm{O}_{2} / \mathrm{N}_{2}$ sorption thermodynamics and geometries do not imply great potential use of the investigated materials for $\mathrm{O}_{2} / \mathrm{N}_{2}$ separation or efficient high density storage. In contrast to pure DFT, GGA functionals supplying our density functional with $25 \%$ Hartree-Fock exchange (PBE0) on the frontier lone pair electrons, helps to correctly identify the structures and magnitudes of the corresponding interactions at a qualitative level, but it still does not seem to be able to accurately predict the trend in the oxygen binding with respect to each divalent $3 \mathrm{~d}$ transition metal ion in the series. Its accuracy towards binding of small singlet molecules like $\mathrm{CO}_{2}$ and $\mathrm{CH}_{4}$ is, on the other hand, preserved. At the very final stages of this manuscript preparation we noticed that other authors have also measured $\mathrm{O}_{2}$ and $\mathrm{N}_{2}$ adsorption at high loadings in one of the investigated here frameworks, namely the CPO-27-Co ${ }^{51}$, using single crystal X-ray diffraction techniques. Their results, being similar to ours, also suggest that both species are in a physisorption regime at the $\mathrm{Co}(\mathrm{II})$ site with the $\mathrm{N}_{2}$ molecule in a nearly straight end on geometry and the $\mathrm{O}_{2}$ molecule in a tilted geometry. Notably these authors also observed orientational disorder in the guest species, precluding accurate intramolecular bond length determination.

\section{Supporting Information.}


Materials synthesis procedures, $\mathrm{N}_{2}$ and $\mathrm{O}_{2}$ sorption isotherms, details of the $\mathrm{Q}_{\mathrm{st}}$, calculation, Rietveld refinement plots and obtained lattice parameters, DFT total density of states plots, cif files of the refined structures. This material is available free of charge via the Internet at http://pubs.acs.org.

\section{Corresponding authors}

Emai1: pageorgiev@yahoo. co.uk (Peter A. Gergiev). Te1: +359028161470

\section{Acknowledgments}

This work is based on experiments performed at the Swiss spallation neutron source SINQ, Paul Scherrer Institute, Villigen, Switzerland. We thank HZB for the allocation of neutron beamtime. This project has received funding from the European Union's Seventh Framework Programme for research, technological development and demonstration under the NMI3-II Grant number 283883. During parts of this work PAG has been supported by the Project "Beyond Everest" under EU programme REGPOT-2011-1. MHR and PDCD acknowledge the support from the Research Council of Norway through the FRINATEK program (grant 221596) and ISP-KJEMI program (grant 209339). MF wishes to acknowledge funding from the European Union's Seventh Framework Programme (FP7/2007-2013) under Grant Agreement No. 290605 (PSIFELLOW/COFUND).

\section{References}

(1) Whittaker, J.W. Free Radical Catalysis by Galactose Oxidase. Chem. Rev. 2003, 103, 23472363. 
(2) Bento, I.; Carrondo, M. A.; Lindley, P. F. Reduction of dioxygen by enzymes containing copper. J. Biol. Inorg. Chem. 2006, 11, 539-547.

(3) Li, Ye-Fei; Aschauer, U.; Chen, J.; Selloni, A. Adsorption and Reactions of $\mathrm{O}_{2}$ on Anatase $\mathrm{TiO}_{2}$. Acc. Chem. Res. 2014, 47, 3361-3368.

(4) Liu, L.; Liu, Q.; Zheng, Y.; Wang, Z.; Pan, C.; Xiao, W. $\mathrm{O}_{2}$ Adsorption and Dissociation on A Hydrogenated Anatase (101) Surface. J. Phys. Chem. C 2014, 118, 3471-3481.

(5) Preda, G.; Migani, A.; Neyman, K. M.; Bromley, S.T.; Illas, F.; Pacchioni, G. Formation of Superoxide Anions on Ceria Nanoparticles by Interaction of Molecular Oxygen with $\mathrm{Ce}^{3+}$ Sites. J. Phys. Chem. C 2011, 115, 5817-5822.

(6) Gionco, C.; Giamello, E.; Mino, L.; Paganini, M. C. The interaction of oxygen with the surface of $\mathrm{CeO} 2-\mathrm{TiO} 2$ mixed systems: an example of fully reversible surface-to-molecule electron transfer. PCCP 2014, 16, 21438-21445.

(7) Beznis, N. V.; Weckhuysen, B. M.; Bitter, J. H. Cu-ZSM-5 Zeolites for the Formation of Methanol from Methane and Oxygen: Probing the Active Sites and Spectator Species. Catal. Lett. 2010, 138, 14-22.

(8) DeCoste, J. B.; Weston, M. H.; Fuller, P. E.; Tovar, T. M.; Peterson, G. W.; LeVan, M. D.; Farha, O. K. Metal-Organic Frameworks for Oxygen Storage. Angew. Chem. Int. Ed. 53 (2014) 5358.

(9) Saha, R.; Joarder, B.; Roy, A. S.; Islam, S. M.; Kumar, S.; Simultaneous Presence of Both Open Metal Sites and Free Functional Organic Sites in a Noncentrosymmetric Dynamic Metal-Organic Framework with Bimodal Catalytic and Sensing Activities. Chem. Eur. J., 2013, 19, 16607.

(10) Xamena, F. L.; Gascon, J. Eds.; Metal Organic Frameworks as Heterogeneous Catalysts, Royal Society of Chemistry, Cambridge, 2013. 
(11) Yu, D.; Yazaydin, A. O.; Lane, J. R.; Dietzel, P. D. C.; Snurr, R. Q. A combined experimental and quantum chemical study of $\mathrm{CO}_{2}$ adsorption in the metal-organic framework $\mathrm{CPO}-27$ with different metals. Chem. Sci., 2013, 4, 3544-3556.

(12) Dietzel, P. D. C.; Morita, Y.; Blom, R.; Fjellvåg, H. An in situ high-temperature single-crystal investigation of a dehydrated metal-organic framework compound and field-induced magnetization of one-dimensional metal-oxygen chains. Angew. Chem. Int. Ed., 2005, 44, 6354-6358.

(13) Dietzel, P. D. C.; Panella, B.; Hirscher, M.; Blom, R.; Fjellvåg, H. Hydrogen adsorption in a nickel based coordination polymer with open metal sites in the cylindrical cavities of the desolvated framework. Chem. Commun., 2006, 959-961.

(14) Dietzel, P. D. C.; Blom, R.; Fjellvåg, H. Base-Induced Formation of Two Magnesium MetalOrganic Framework Compounds with a Bifunctional Tetratopic Ligand. Eur. J. Inorg. Chem., 2008, 3624-3632.

(15) Zhou, W.; Wu, H.; Yildirim, T. Enhanced H2 Adsorption in Isostructural Metal-Organic Frameworks with Open Metal Sites: Strong Dependence of the Binding Strength on Metal Ions. J. Am. Chem. Soc., 2008, 130, 15268-15269.

(16) Rosi, N. L.; Kim, J.; Eddaoudi, M.; Chen, B.; O'Keeffe, M.; Yaghi, O. M. Rod Packings and Metal-Organic Frameworks Constructed from Rod-Shaped Secondary Building Units. J. Am. Chem. Soc., 2005, 127, 1504-1518.

(17) Bloch, E. D.; Murray, L. J.; Queen, W. L.; Chavan, S.; Maximoff, S. N.; Bigi, J. P.; Krishna, R.; Peterson, V. K.; Grandjean, F.; Long, G. J.; Smit, B.; Bordiga, S.; Brown, C. M.; Long, J. R. Selective Binding of $\mathrm{O}_{2}$ over $\mathrm{N}_{2}$ in a Redox-Active Metal-Organic Framework with Open Iron(II) Coordination Sites. J. Am. Chem. Soc., 2011, 133, 14814-14822.

(18) Märcz, M.; Johnsen, R. E.; Dietzel, P. D. C.; Fjellvåg, H. The iron member of the CPO-27 coordination polymer series: Synthesis, characterization, and intriguing redox properties. Micropor. Mesopor. Mat., 2012, 157, 62-74. 
(19) Calleja, G.; Sanz, R.; Orcajo, G.; Briones, D.; Leo, P.; Martínez, F. Copper-based MOF-74 material as effective acid catalyst in Friedel-Crafts acylation of anisole. Catal. Today, 2014, 227, $130-137$.

(20) Sanz, R.; Martinez, F.; Orcajo, G.; Wojtas, L.; Briones, D. Synthesis of a honeycomb-like Cubased metal-organic framework and its carbon dioxide adsorption behaviour. Dalton Trans., 2013, 42, 2392-2398.

(21) Rosnes, M. H.; Opitz, M.; Frontzek, M.; Lohstroh, W.; Embs, J. P.; Georgiev, P. A.; Dietzel, P. D. C. Intriguing differences in hydrogen adsorption in CPO-27 materials induced by metal substitution. J. Mater. Chem. A, 2015, 3, 4827-4839.

(22) Díaz-García, M.; Sánchez-Sánchez, M. Synthesis and characterization of a new Cd-based metal-organic framework isostructural with MOF-74/CPO-27 materials. Micropor. Mesopor. Mat., 2014, 190, 248-254.

(23) Dietzel, P. D. C.; Johnsen, R. E.; Blom, R.; Fjellvåg, H. Structural Changes and Coordinatively Unsaturated Metal Atoms on Dehydration of Honeycomb Analogous Microporous Metal-Organic Frameworks. Chem. Eur. J., 2008, 14, 2389-2397.

(24) Queen, W. L.; Bloch, E. D.; Brown, C. M.; Hudson, M. R.; Mason, J. A.; Murray, L. J.; Ramirez-Cuesta, A. J.; Peterson, V. K.; Long, J. R. Hydrogen adsorption in the metal-organic frameworks $\mathrm{Fe}_{2}\left(\right.$ dobdc) and $\mathrm{Fe}_{2}\left(\mathrm{O}_{2}\right)$ (dobdc) . Dalton Trans., 2012, 41, 4180-4187.

(25) Rieth, A. J.; Tulchinsky, Y.; Dincă, M. High and Reversible Ammonia Uptake in Mesoporous Azolate Metal-Organic Frameworks with Open Mn, Co, and Ni Sites. J Am Chem Soc., 2016, 138, 9401-9404.

(26) a. Parkes, M.V.; Sava Gallis, D. F.; Greathouse, J.A.; Nenoff, T.M. Effect of Metal in $\mathrm{M}_{3}(\mathrm{btc})_{2}$ and $\mathrm{M}_{2}$ (dobdc) MOFs for $\mathrm{O}_{2} / \mathrm{N}_{2}$ Separations: A Combined Density Functional Theory and Experimental Study. J. Phys Chem. C 119 (2015) 6556-6567: b. Parkes, M.V.; Greathouse, J.A.; 
Hart, D. B.; Sava Gallis, D. F.; Nenoff, T.M. Ab initio molecular dynamics determination of competitive $\mathrm{O}_{2}$ vs. $\mathrm{N}_{2}$ adsorption at open metal sites of $\mathrm{M}_{2}$ (dobdc). PCCP, 2016, 18, 11528-11538. (27) a.Wang, Y.; Yang, J.; Li, Z.; Zhang, Z.; Li, J.; Yang, Q,; Zhong, C. Computational study of oxygen adsorption in metal-organic frameworks with exposed cation sites: Effect of framework metal ions. RSC Adv., 2015, 5, 33432-33437; b. Zhang, M.; Huangab, X.; Chen, C. DFT insights into the adsorption of NH3-SCR related small gases in Mn-MOF-74. PCCP, 2016, 18, 2885428863.

(28) Fischer, P.; Frey, G.; Koch, M.; Könnecke, M.; Pomjakushin, V.; Schefer, J.; Thut, R.; Schlumpf, N.; Bürge, R.; Greuter, U.; Bondt, S.; Berruyer, E. High-resolution powder diffractometer HRPT for thermal neutrons at SINQ. Physica $B$, 2000, 276-278, 146-147. (29) Fischer, P.; Keller, L.; Schefer, J., Kohlbrecher, J. Neutron diffraction at SINQ. Neutron, 2000, 11, 19-21.

(30) Többens, D. M.; Stüßer, N.; Knorr, K.; Mayer, H. M.; Lampert, G. E9: The new highresolution neutron powder diffractometer at the Berlin Neutron Scattering Center. Materials Science Forum, 2001, 378-381, 288-293.

(31) Rodríguez-Carvajal, J. Recent advances in magnetic structure determination by neutron Powder diffraction. Physica B, 1993, 192, 55-69.

(32) Gonze, X.; Amadon, B.; Anglade, P. M.; Beuken, J. M.; Bottin, F.; Boulanger, P.; Bruneval, F.; Caliste, D.; Caracas, R.; Côté, M.; Deutsch, T.; Genovese, L.; Ghosez, P.; Giantomassi, M.; Goedecker, S.; Hamann, D. R.; Hermet, P.; Jollet, F.; Jomard, G.; Leroux, S.; Mancini, M.; Mazevet, S.; Oliveira, M. J. T.; Onida, G. Pouillon, Y.; Rangel, T.; Rignanese, G. M.; Sangalli, D.; Shaltaf, R.; Torrent, M.; Verstraete, M. J.; Zerah, G.; Zwanziger, J. W. ABINIT: First-principles approach to material and nanosystem properties. Comput. Phys. Commun., 2009, 180, 2582-2615.

(33) F. Bottin, S. Leroux, A. Knyazev and G. Zérah, Large-scale ab initio calculations based on 
three levels of parallelization. Comp. Mater. Sci., 2008, 42, 329-336.

(34) Zhang, Q.; Li, B.; Chen, L.; First-Principles Study of Microporous Magnets M-MOF-74 (M = Ni, Co, Fe, Mn): the Role of Metal Centers. Inorg. Chem. 2013, 52, 9356-9362.

35 P. D. C. Dietzel, P. A. Georgiev, J. Eckert, R. Blom, T. Strässle, T. Unruh, Chemical Communications 2010, 46, 4962-4964.

36 P. D. C. Dietzel, V. Besikiotis, R. Blom, Journal of Materials Chemistry 2009, 19, 7362-7370.

(37) Grimme, S. Semiempirical GGA-type density functional constructed with a long-range dispersion correction. J. Comput. Chem., 2006, 27, 1787-1799.

(38) Zhou, Y., Wei, W., Yang, J., Sun, Y., Zhou, L. Adsorption of Oxygen on Superactivated Carbon. J. Chem. Eng. Data 2005, 50, 1068-1072.

(39) Calorimetric Heats of Adsorption and Adsorption Isotherms. 2. $\mathrm{O}_{2}, \mathrm{~N}_{2}, \mathrm{Ar}, \mathrm{CO}_{2}, \mathrm{CH}_{4}, \mathrm{C}_{2} \mathrm{H}_{6}$, and $\mathrm{SF}_{6}$ on NaX, H-ZSM-5, and Na-ZSM-5 Zeolites. Langmuir 1996, 12, 5896-5904.

(40) Wang, Y., Helvensteijn, B., Nizamidin, N., Erion, A.M., Steiner, LA., Mulloth, L.M., Luna, M., LeVan, M.D. High Pressure Excess Isotherms for Adsorption of Oxygen and Nitrogen in Zeolites. Langmuir 2011, 27, 10648-10656.

(41) MOF Crystal Chemistry Paving the Way to Gas Storage Needs: Aluminum-Based soc-MOF for CH4, O2, and CO2 Storage. J. Am. Chem. Soc. 2015, 137, 13308-13318.

(42) Thonhauser, T.; Zuluaga, S.; Arter, C. A.; Berland, K.; Schroder, E.; Hyldgaard, P. Spin Signature of Nonlocal Correlation Binding in Metal-Organic Frameworks. Phys. Rev. Lett. 2015, $115,136402-1$ - 136402-6.

(43) Bloch, E. D., Hudson, M. R., Mason, J. A., Chavan, S., Crocellà, V., Howe, J. D., Lee, K., Dzubak, A. L.; Queen, W. L.; Zadrozny, J.M.; Geier, S. J.; Lin, L.-C.; Gagliardi, L.; Smit, B.; Neaton, J. B.; Bordiga, S.; Brown, C. M.; Long, J. R. Reversible CO Binding Enables Tunable $\mathrm{CO} / \mathrm{H}_{2}$ and $\mathrm{CO} / \mathrm{N}_{2}$ Separations in Metal-Organic Frameworks with Exposed Divalent Metal Cations. J. Am. Chem. Soc. 2014,136, 10752-10761. 
44. Bloch, E. D.; Queen, W. L.; Krishna, R.; Zadrozny, J. M.; Brown, C. M.; Long, J. R. Hydrocarbon separations in a metal-organic framework with open iron(II) coordination sites.

Science 2012, 335, 1606-1610.

45. Zhang, Y. and Yang., W. Comment on "Generalized Gradient Approximation Made Simple”. Phys. Rev. Lett., 1998, 80, 890.

46. Improved adsorption energetics within density-functional theory using revised Perdew-BurkeErnzerhof functionals. Phys. Rev. B, 1989, 59, 7413-7421.

47. Becke, . A.D. Density-functional thermochemistry. III. The role of exact exchange

J. Chem. Phys. 98 (1993) 5648-5652; Lee, C.; Yang, C.W.; Parr, R.G. Development of the ColleSalvetti correlation-energy formula into a functional of the electron density. Phys. Rev. B 37 (1988) 785-789.

48. Adamo, C., Barone, V. Toward reliable density functional methods without adjustable parameters: The PBE0 model. J. Chem. Phys. 1999, 110, 6158-6170.

49. Verma, P., Maurice, M., Truhlar, D.G. Identifying the Interactions That Allow Separation of $\mathrm{O}_{2}$ from $\mathrm{N}_{2}$ on the Open Iron Sites of $\mathrm{Fe}_{2}$ (dobdc). J. Phys. Chem. C, 2015, 119, 28499-28511.

50. Hadjiivanov, K. Identification of Neutral and Charged $\mathrm{N}_{\mathrm{x}} \mathrm{O}_{\mathrm{y}}$ Surface Species by IR Spectroscopy Catal. Rev. Sci. Eng. 2000, 42, 71-144.

51. M. I. Gonzalez, J. A. Mason, E. D. Bloch, S. J. Teat, K. J. Gagnon, G. Y. Morrison, W. L. Queen and J. R. Long Structural characterization of framework-gas interactions in the metalorganic framework $\mathrm{Co}_{2}$ (dobdc) by in situ single-crystal X-ray diffraction Chem. Sci. 2017, DOI: 10.1039/C7SC00449D 